\title{
Experimental investigations on the influence of thermal elements on the structural stability of modern masonry walls
}

\author{
M. Deyazada, B. Vandoren \& H. Degée \\ Construction Engineering Research Group, Hasselt University, Hasselt, Belgium
}

\begin{abstract}
The presence of additional elements specifically aiming at improving the energy efficiency of buildings (thermal layers, disconnections) is known as potentially having a significant impact on the resistance and stability of load-bearing masonry walls. On the one hand, the presence of these thermal elements induces potential weaknesses in the walls, modifying their resistance at local level. On the other hand, these elements also modify the boundary conditions of the walls and are thus likely to have an influence on the buckling behaviour. It is therefore necessary to adjust accordingly the design procedures suggested for instance by Eurocode 6 to check the wall stability against gravity loading. Experimental studies concerning the interaction between thermal performance and structural stability of unreinforced masonry (URM) structures remain however limited. Therefore, the objective of the current study is to develop a better understanding of the behaviour of current URM structures in presence of such thermal layers. A typical example is for instance the presence of a layer of aerated concrete blocks at the bottom of a clay masonry wall. This study includes a comprehensive testing program considering different types of masonry elements subjected to various load conditions. This paper plans to summarise the experimental campaign and the design of the test setup and test specimens. The research work aims on the long term at the identification of the interaction of various parameters (compression level, mortar type, unit type, type of thermal elements) on the strength capacity and stability of URM walls.
\end{abstract}

\section{INTRODUCTION}

An increasing amount of standards and regulations is being considered to satisfy the environmental conditions such as thermal comfort, fire resistance, soundproofing, etc. As a result, the demand on the construction industry has noticeably increased in the direction of optimized construction products with improved thermal insulation of the units, with the potential consequence of modified their mechanical resistance properties. Such products have been introduced to the market since the 1920s as infilled and confined material e.g. (lintels, block, facade wall). Moreover, thermal blocks have been used to raise houses from ground to roof. An example of current and most popular products is autoclaved aerated concrete (AAC), also called by other names Ytong, autoclaved lightweight concrete (ALC), Hebel Block, and Aircrete as displayed in Figure1. It is a light building material made from lime, cement and sand and provides unique characteristics in terms of low thermal conductivity, good fire resistance, and easy and quick insulation. Nevertheless, it has a limited load bearing capacity due to its low compression strength.

One common example of using these blocks in Europe and particularly in Belgium is having

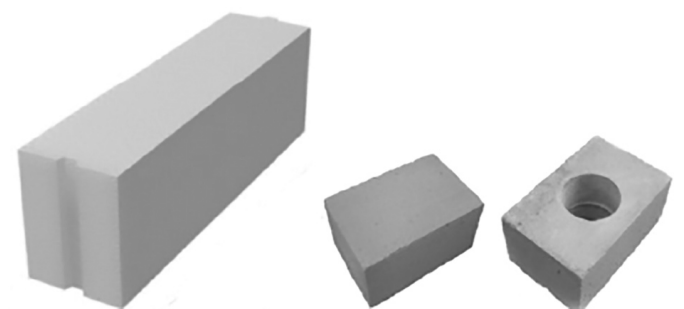

Figure 1. AAC bricks, (Zovkic et al. 2013).

a layer of thermal insulation load bearing blocks situated at the bottom of an unreinforced masonry wall (URM) clay masonry wall as presented in Figure 2. This has become widely used in the modern buildings to reduce the thermal bridge effect. However, there are some concerns on structural behavior of these kinds of composite walls due to the lower resistance of such thermal blocks, and the presence of these isolation blocks at the bottom of the wall, which implies changes in the floorwall joint and consequently on the wall boundary conditions. This clearly affects the local resistance, stiffness, and failure mechanisms of the wall. A question that needs to be answered, however, is how these modifications influence for instance the 

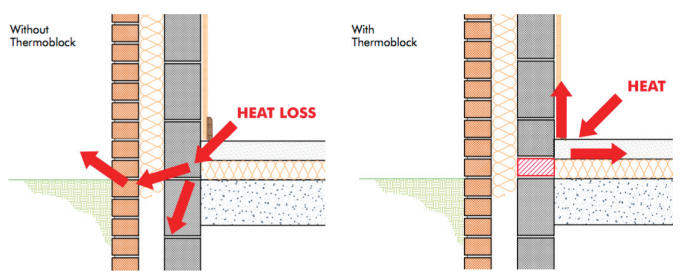

Figure 2. High insulating load bearing brick placed at first layer of URM wall, (Marmox 2015).

stability and strength capacity of masonry wall subjected to various load conditions.

Although the popularity of using hybrid walls (i.e. walls made of more than one type of units) for thermal or acoustic reason is increasing in the construction industry, a limited number of studies have investigated the structural behavior of these elements and in particular their stability when used as load bearing walls. The available research results concerning the structural performance of thermal element (Memari et al. 2008; Penna et al. 2008; Tanner et al. 2005) are essentially focusing on pure AAC systems. However, none of abovementioned studies have investigated the influence of thermal elements on the local behavior of composite masonry walls regarding structural stability. Moreover, current design codes and guidelines e.g. (Eurocode 6, Eurocode 8, STS22) are silent on the effect of these materials and lack accepted design methods to determine the design resistance and stability for masonry walls including thermal insulation bricks.

\section{SCOPE AND OBJECTIVES}

The investigation will focus on the most common kinds of high insulating load bearing bricks (compressive strength between 5 and $15 \mathrm{~N} / \mathrm{mm}^{2}$ ) in North-western Europe that are designed particularly to replace the layer of block or brick at the bottom of a wall to eliminate the thermal bridge effect.

In such a context, the purpose of the study is to conduct a detailed experimental investigation on URM walls including energy-efficient material placed as bottom layer of the wall, and subjected to combination of vertical and lateral bending loads. The objectives are to improve the understanding of the structural behavior of unreinforced loadbearing masonry structures composed with high insulating load bearing brick, and to identify their failure mechanism in view of developing adapted design procedures. At the mean time, the impact of these elements on the structural stability of the wall will also be examined. In the long term, the inter- action of various parameters (e.g. mortar type, type of thermal units, level of axial load, lateral bending load, eccentricity) on strength capacity and resistance of URM wall will be investigated. Using the experimental data, a simplified finite element model capable of capturing the observed stability behavior of the thermal-masonry hybrid wall under varying axial and transverse load for particular combination will be performed. The model will incorporate a cantilever wall with spring elements attached at the base of the wall. The geometrical, material properties of the wall, and the loads applied (self weight, axial load, transverse out-of plane load) are corresponded to the experimental data. These springs (i.e. rotational spring, translation spring) will be in particular used to represent the observed axial load-bending moment interaction $(N-M)$ displacement and the consequent flexural restraint on the walls. The validated model output such as force-moment interaction stability curves, moment curvature curves and force displacement curves will be used to illustrate the influence of considered parameters (thermal elements, load eccentricity, mortar) on the stability and resistance of masonry. The concluded behavior will be extended to larger-scale models to obtain the stability behavior of entire structural elements. These developments are thus aiming at filling the gap in the codes and proposing suitable design guidelines and formulas for composite masonry walls.

\section{EXPERIMENTAL PROGRAM}

\subsection{Test set-up}

The test setup that will be used for out-of-plane characterization is presented in Figure 3. The experimental tests will be performed on wallet specimens $(1 \mathrm{~m} \times 1 \mathrm{~m})$. The structural configuration comprises an unreinforced cantilever wall standing between a reinforced concrete RC beam at its top and a steel plate fixed to the steel frame beam at the bottom. The steel plate will be positioned in a way to allow accounting for different load eccentricities. The experimental tests will be conducted in two phases. In the first stage, the compression axial load will be applied to the wall by means of two actuators attached to the steel reaction frame (force controlled) until a given level. The axial load will then be kept constant. The second stage will then consists in imposing a lateral out-of-plane deformation by resorting to a displacement-controlled horizontal actuator.

The lateral displacement will be increased until failure of the wall. The actuators (horizontal, vertical) are connected to the wall through a loading 

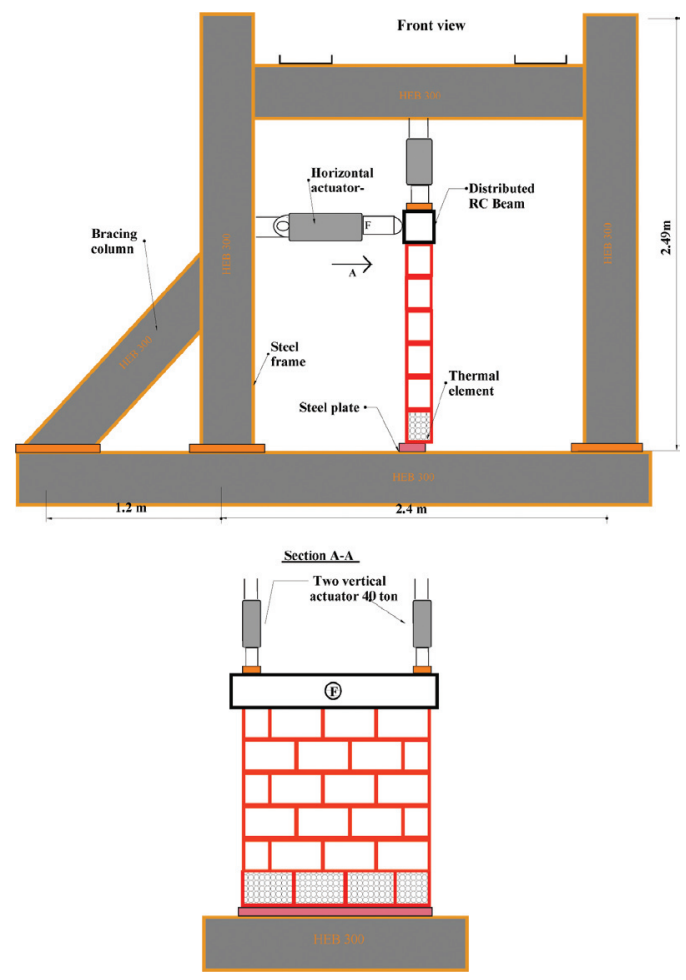

Figure 3. Test set-up for out-of-plane characterization.

beam in order to distribute the load uniformly. The lateral deflections of the walls will be measured by means of displacement transducers LVDTs and the applied load will be recorded throughout loading by load cells.

\subsection{Parameters for composite URM specimen}

Our main aim in this study is to investigate the influence of thermal elements on stability. Numerous studies have highlighted numbers of parameters, which affect the structural performance and stability of URM walls such as wall slenderness $(\mathrm{h} / \mathrm{t})$, eccentricities, boundary condition, component material properties, and load applied (Bean Popehn et al. 2008; Schultz \& Mueffelman 2003). Masonry walls have low tensile strength, the vertical compression load $P$ have a determining effect on the wall, for it induces changes in the eccentricity $e$, and consequently the action of the eccentricity applied force cause member to bend and deflect, producing moments equal to moment $(P \times e)$ and second order moment from lateral deflection $(\mathrm{P} \times$ deflection $)$. As a result, flexural tension will crack the masonry wall and reduce the moment inertia of the member (Colville 2001). Bending from out-of-plan load will increase the tendency for instability through generating more flexural tensile stresses in the wall, thus reducing the effective depth of the wall cross-section and causing larger lateral deflection (Bean Popehn et al. 2008). Therefore the relationship between critical axial loads and maximum bending moment on URM walls at the limit of stable behavior need to be investigated. In our case, a full bending moment axial load interaction diagram will be obtained for the small-scale specimens. To accomplish that, we will apply five different levels of axial loads on the specimens (the values obtained represent $15 \%$, $25 \%, 40 \%, 55 \%$, and $70 \%$ of the maximum vertical resistance, $N_{R d}$ of the composite masonry wall). Then, an increasing lateral load will be subjected to the specimens until the wall fail. As a result, the maximum bending moment capacity corresponding to each axial load level will be identified. After that, a N-M interaction curve can be extrapolated to larger-scale specimens by resorting to well-calibrated finite element models.

The materials component used to build the masonry walls have different mechanical properties (compressive strength, tensile strength, etc.) that are affecting the structural performance of the wall regarding its failure mechanism and resistance capacity. As the main focus of this study is to check the impact of the thermal elements on the structural stability of masonry walls, the type of thermal insulation bricks used as bottom layer of the masonry specimen is considered as the first important parameter. We have selected from the market three types of load bearing thermal insulation bricks (T1, T2, T3) taking into account the following: (i) cover the most common types of energy efficient elements in North-Western Europe that are designed particularly to replace the course of block or brick at the bottom of a wall to eliminate the thermal bridge effect at that point, (ii) include elements that are not being classified in current codes (e.g. T3), and (iii) select elements with a variety of material, structural and geometrical properties.

The type of masonry unit is the next parameter. According to STS 22 guideline regarding design masonry wall composed with thermal bricks as bottom layer, the configuration of bricks of upper masonry layer is being claimed to affect the compressive strength resistance of the bottom layer of thermal insulation bricks through reduction factor $\mu$ (determined based on experimental test). On the other hand, the thermal insulation layer is being assumed by same guideline to act as hinged or fixed support to the upper masonry layer depend on the ratio between elastic modulus $E$ of the thermal insulation brick to the one of the masonry unit i.e. (if the $E$ of the masonry with thermal brick 
$<0.1 \times E$ of the overlying masonry, the thermal brick acts more or less like a hinge, If the ratio 1, thermal layer can be considered as fixed support at the bottom). Therefore, to take into account these approaches and to be able to verify it effectively based on experimental evidence, three masonry units from two different materials with significant different in compressive strength, have been selected: clay brick (C1), clay block (C2), Concrete block (B1).

Mortar is the third parameter considered. Masonry is a composite of units and mortar and the strength of the wall is thus depending on the characteristics of both components. Besides, resistance behavior of masonry wall is in several cases determined based on friction bond between mortar and bricks (Tomaževič 1999). This indicates that using different kinds of mortar could affect the failure mechanism and the crack pattern (i.e. line, tooth) that are likely to occur. In different circumstances, producing mortar with quality in accordance with code specification is not always guaranteed. Hence, this study will comprise testing walls with two types of mortar from different qualities (M10, M5).

The axial load eccentricity is the last variable considered in our experimental sets. The eccentricity is recognized to affect the stability (Bean Popehn et al. 2008) and considered in the current codes (Eurocode 6 2005) through a reduction factor decreasing the design value of the vertical resistance of a URM compression element. We will consider different amplitude of load eccentricity and study its influence on the local behavior and resistance. Three eccentricities will be considered: $e=0, \mathrm{t} / 12$ and $t / 6$. Parameters applied on the URM wall are presented in Figure 4.

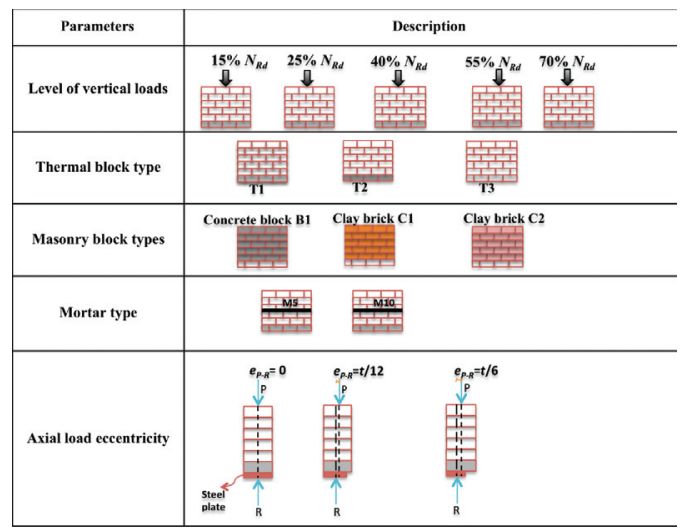

Figure 4. Overview of parameters applied to composite URM specimen.

\subsection{Material properties, geometry for masonry specimens}

The wall configuration types considered in the experiment is one-way spanning wall (supported only at their horizontal edges) and the difference between specimens is basically the mortar type, the thermal elements used as first layer of the wall, and the masonry units of the upper layer. Geometric details and performance criteria of the masonry units (regular unit, insulation bricks) and the mortar are summarized in Table 1 and 2. The presented values of the materials are taken from the manufacture and will be verified in the laboratory.

The dimensions of the specimens are defined in such a way to be tested with the available facilities in the Application Centre for Concrete and Construction of Hasselt University and defined based on the estimation of the experimental out-of-plane lateral load, taking into account the failure modes that is likely to occur (flexural failure, instability failure). Exact dimensions of the masonry panels are presented in Figures 5-9.

\subsection{Design criteria for composite URM wall}

As previously mentioned, the experiment will focus on cantilever URM walls constructed by various masonry units and thermal blocks, and subjected to predefined axial compression loads (five different levels) and increasing lateral out-of-plane bending load. The values of these proposed acting vertical

Table 1. Geometric and performance criteria of masonry units for planned tests.

\begin{tabular}{|c|c|c|c|}
\hline $\begin{array}{l}\text { Brick } \\
\text { type }\end{array}$ & $\begin{array}{l}\text { Nominal dimension } \\
\mathrm{bt} \mathrm{h}\end{array}$ & $\begin{array}{l}\text { Standards } \\
\text { specification }\end{array}$ & $\begin{array}{l}\text { Compressive } \\
\text { strength }\end{array}$ \\
\hline- & $\mathrm{mm} \mathrm{mm} \mathrm{mm}$ & - & $\mathrm{N} / \mathrm{mm}^{2}$ \\
\hline $\mathrm{C} 1$ & $\begin{array}{lll}300 & 140 & 176.7\end{array}$ & EN771-1 & 13 \\
\hline $\mathrm{C} 2$ & $288 \quad 138 \quad 184$ & EN771-1 & 25 \\
\hline B1 & $290 \quad 140 \quad 190$ & EN771-3 & 8 \\
\hline $\mathrm{T} 1$ & $600 \quad 140 \quad 200$ & EN771-4 & 5 \\
\hline $\mathrm{T} 2$ & $290 \quad 138 \quad 195$ & EN771-1 & 15 \\
\hline $\mathrm{T} 3$ & $\begin{array}{lll}600 & 140 & 100\end{array}$ & EN771-4 & 10 \\
\hline
\end{tabular}

Table 2. Geometric and performance criteria of masonry mortar for planned tests.

\begin{tabular}{lllc}
\hline Mortar & & Thickness & $\begin{array}{l}\text { Compressive } \\
\text { strength }\end{array}$ \\
\hline Name & Type & $\mathrm{mm}$ & $\mathrm{N} / \mathrm{mm} 2$ \\
\hline M5 & General purpose & 5 & 5 \\
M10 & General purpose & 5 & 10 \\
\hline
\end{tabular}



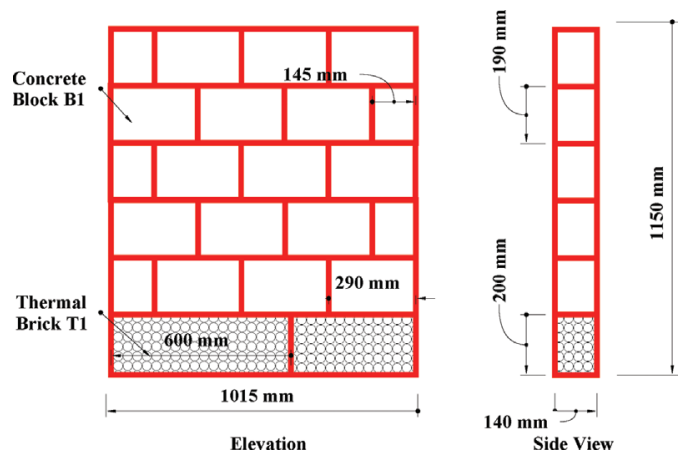

Figure 5. Wall geometry for concrete (B1) URM wall composed with thermal block (T1).
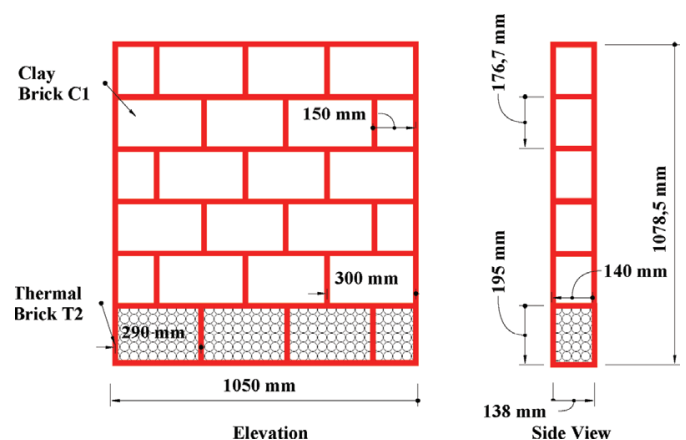

Figure 6. Wall geometry for clay (C1) URM wall composed with thermal brick (T2).
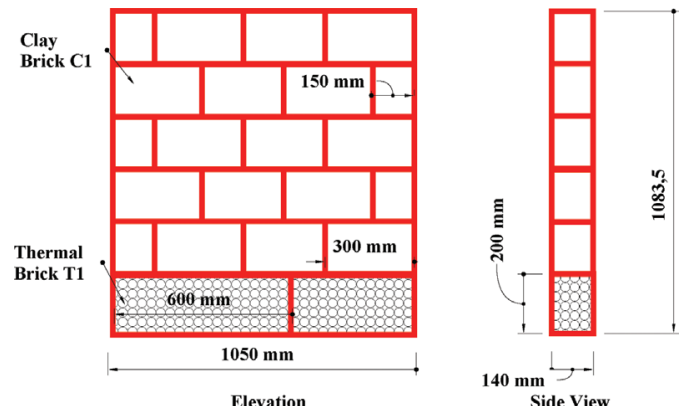

Figure 7. Wall geometry for clay $(\mathrm{C} 1) \mathrm{URM}$ wall composed with thermal block (T1).

loads are based on calculation of masonry walls design strength according to (Eurocode 6 2005; STS22 2016) guideline. The latter guideline states that there is not yet a design method to obtain design resistance for URM masonry wall composed with isolated thermal layer at the first raw of the wall on which everybody could agree. To calcu-
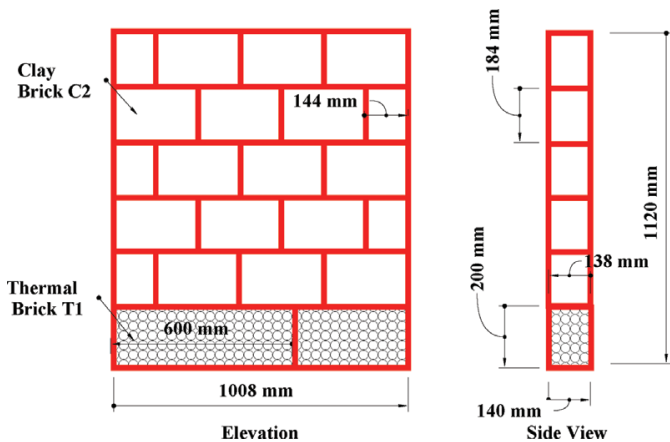

Figure 8. Wall geometry for clay (C2) URM wall composed with thermal block (T1).
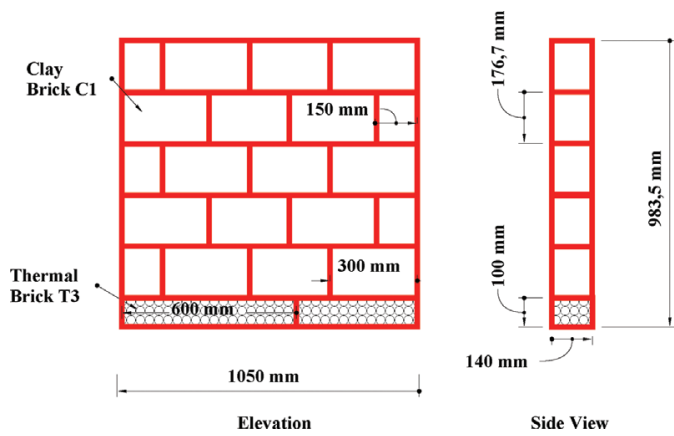

Figure 9. Wall geometry for clay (C1) URM wall composed with thermal block (T3).

late the characteristic compressive strength $f_{k}$ for a layer of masonry units (ordinary masonry units, AAC bricks) filled with general-purpose mortar, Equation 1 is used. For thermal blocks T2 and T3 (not explicitly grouped in Eurocode 6), approximated values of the characteristics compressive strength have been obtained using the formula and coefficients of AAC bricks or regular masonry units; taking in account the manufacture declaration (i.e. T3 assumed by manufacture as AAC brick following EN771-4, so $K=0.6, \alpha=0.65, \beta=0.25$; T2 assumed as clay block from group 2 following EN771- 1 , so $\mathrm{K}=0.5, \alpha=0.65, \beta=0.25$ ).

$f_{k}=K f_{b}{ }^{\alpha} f_{m}{ }^{\beta}$

where $f_{b}=$ is normalized mean compressive strength of a masonry unit; $f_{m}=$ compressive strength of masonry mortar; $K, \alpha, \beta=$ are constants; and $f_{k}=$ characteristic compressive strength.

Table 3 presents the characteristics compressive strength values for the bottom thermal layer (for thermal bricks T1, T2, T3) and the top masonry 
Table 3. Characteristic compressive strength of the composite masonry specimen.

\begin{tabular}{lll}
\hline Brick & $f_{k}, \mathrm{M} 5 f_{k}, \mathrm{M} 10$ & \\
\hline Name & $\mathrm{N} / \mathrm{mm}^{2}$ & $\mathrm{~N} / \mathrm{mm}^{2}$ \\
\hline T1 & 2.54 & 3.04 \\
T2 & 4.34 & 5.17 \\
T3 & 4 & 4.76 \\
C1 & 3.96 & 4.71 \\
C2 & 6.06 & 7.2 \\
B1 & 2.88 & 3.34 \\
\hline
\end{tabular}

layer (for masonry unit $\mathrm{B} 1, \mathrm{C} 1, \mathrm{C} 2$ ) in combination with two types of general-purpose mortar (M5, M10).

An estimation of the maximum vertical loads that could be resisted by the masonry specimens is carried out according to the design method stated in the Belgium guideline STS 22 taking into account the hypothesis that the tensile strength is equal to zero and the plane section remains plane. The procedures consist in the calculation of vertical design resistances for the composite wall assuming that the wall consist of two layers (top layer present masonry units, bottom layer present insulation bricks). Design vertical resistance $N_{R d}$ for each layer is obtained separately. The weakest layer, which has lower vertical design strength, is taken into consideration as the reference resistance. In other words, it is conservatively assumed that the resistance of one layer is the same as the resistance of a wallet. The design vertical resistances of both layers are basically function of design compressive strength of the wall (characteristic compressive strength over partial safety factor), capacity reduction factor, and the thickness of the wall as presented in Equation 2 and 3. Nevertheless, the design compressive strength of the insulating materials (for bottom layer) has been multiplied by a factor $\mu$ (assumed currently equal to 1), which is depending on the configuration of the thermal insulation brick and of the masonry units of the second layer. It is suggested that this factor is determined on the basis of tests on two masonry units, with a joint corresponding to reality, as presented in Figure 10.

This test will be carried out in our laboratory to validate the STS proposal and the value of $\mu$ will be adjusted accordingly. The reduction factor $\phi_{1,2}$ at the bottom of the wall is obtained taking into account the effect of eccentricity as presented in Equation 4. The eccentricity is calculated here as summation of geometrical axial load eccentricity assumed $(0, t / 12, t / 6)$ and eccentricity $(M / N)$ arises from the out-of-plane bending, axial load applied

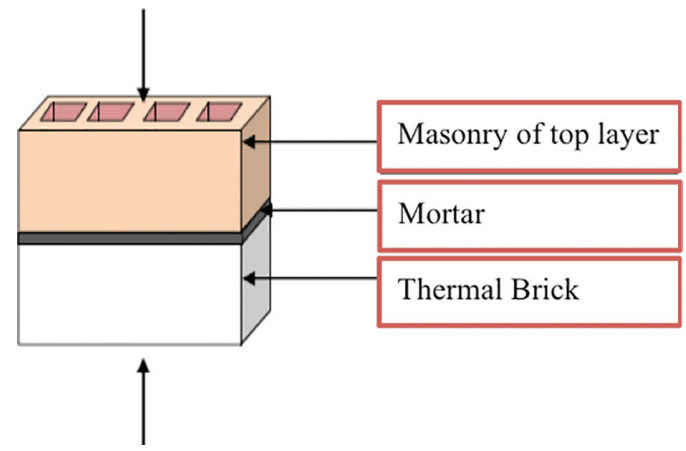

Figure 10. Example of compressive strength test configuration to obtain $\mu$ (STS22 2016).

to the wall. The safety factor $\gamma_{m}$ is assumed to be equal to 1 in order to obtain the most likely value of the resistance.

$N_{R d}=\phi_{1}\left(\mu f_{d 1}\right) t$

$N_{R d}=\phi_{2} f_{d 2} t$

where $\phi_{1,2}=$ reduction factor; $t=$ wall thickness; $f_{d l}=$ design compressive strength for thermal bricks and it is equal to $f_{k} / \gamma_{m} ; f_{d 2}=$ the design compressive strength of the overlying masonry and it is equal to $f_{k} / \gamma_{m} ; \mu=$ a reduction factor which takes into account the configuration of bricks of the upper masonry; and $N_{R d}=$ design value of the vertical resistance of a masonry wall.

$\phi_{i}=1-2 e_{e} / t$

Where $\phi_{\mathrm{i}}=$ reduction factor; $e_{e}=$ is the eccentricity at the top or the bottom of the wall (to be greater than $0.05 t) ; t=$ is equal to wall thickness.

Tables 4, 5 and 6 summarize the design values of the vertical resistance (lower value) for the composite masonry walls of thermal insulation bricks (T1, T2, T3) in the bottom layer, and masonry units $(\mathrm{B} 1, \mathrm{C} 1, \mathrm{C} 2)$ in the top layer in combination with two types of mortar, and three amplitudes of eccentricities $(e=0, e=t / 12, e=t / 6)$.

An assessment of the maximum lateral out-of plane loads that the masonry specimens could resist is again obtained taking into account the assumption that tensile strength is assumed to be zero and the plane section remains plane. The procedure consists in the calculation of the design value of the moment of resistance for the composite masonry walls in the direction parallel to the bed joint. The design moment is a function of 
Table 4. Design values of the vertical resistance for the composite masonry wall with $e=0$.

\begin{tabular}{lll}
\hline Wall composed & $N_{R d}, M 10$ & $N_{R d}, M 5$ \\
\hline with & $\mathrm{kN} / \mathrm{m}$ & $\mathrm{kN} / \mathrm{m}$ \\
T1 \& C1 & 383 & 322 \\
T2 \& C1 & 594 & 499 \\
T3 \& C1 & 594 & 499 \\
T1 \& C2 & 383 & 322 \\
T1 \& B1 & 383 & 322 \\
\hline
\end{tabular}

Table 5. Design values of the vertical resistance for the composite masonry wall with $e=t / 12$.

\begin{tabular}{lll}
\hline Wall composed & $N_{R d}, M 10$ & $N_{R d}, M 5$ \\
\hline with & $\mathrm{kN} / \mathrm{m}$ & $\mathrm{kN} / \mathrm{m}$ \\
\hline T1 \& C1 & 353 & 298 \\
T2 \& C1 & 547 & 460 \\
T3 \& C1 & 547 & 460 \\
T1 \& C2 & 353 & 298 \\
T1 \& B1 & 353 & 298 \\
\hline
\end{tabular}

Table 6. Design values of the vertical resistance for the composite masonry wall with $e=t / 6$.

\begin{tabular}{lll}
\hline Wall composed & $N_{R d}, M 10$ & $N_{R d}, M 5$ \\
\hline with & $\mathrm{kN} / \mathrm{m}$ & $\mathrm{kN} / \mathrm{m}$ \\
\hline T1 \& C1 & 285 & 240 \\
T2 \& C1 & 442 & 372 \\
T3 \& C1 & 442 & 372 \\
T1 \& C2 & 285 & 240 \\
T1 \& B1 & 285 & 240 \\
\hline
\end{tabular}

the elastic section modulus $Z$, and design flexure strength $f_{x d}$ of the wall as presented in Equation 5. Similarly to aforementioned design procedures of composite wall against vertical load, conservative approach has been considered; assuming the flexural resistance of one layer is the same as the resistance of a wallet. Thus, the flexure strength has been obtained for the two layers (top layer present masonry units, bottom layer present insulation bricks). The weakest layer, which has lower flexural strength is taking into consideration as the reference resistance. The flexural strength values of thermal insulation bricks (T2, T3) in combination with normal mortar have been extrapolated to that one of AAC or ordinary masonry units (taking into account manufacture declaration) since no tests have been conducted yet concerning the flexural strength characterization (per EN-1052-2) for such case.

The favorable effect of the vertical stress on the flexural resistance has been taken into account using the apparent flexural strength, $f x d l$,app, given by Equation 6, thus $f_{x d}$ has modified accordingly. The safety factor $Y_{m}$ is assumed here to be equal to 1 to get the most likely value of the resistance.

$$
M_{R d}=f_{x d} Z
$$

where $f_{x d}=$ design flexural strength and it is equal to $f_{k} / Y_{m} ; Z=$ elastic section modulus; and $M_{R d}=$ design value of the moment resistance of a masonry wall.

$$
f_{x k, a p p}=f_{x k}+\sigma_{d}
$$

where $f_{x k}=$ flexural strength; $\sigma_{d}=$ design compressive strength (not greater than $0.2 f_{d}$ ); and $f_{x k, \text { app }}=$ apparent flexural strength.

The corresponding maximum horizontal jack load $F$ that could be applied to the specimens is then derived i.e. (for cantilever wallets, $F_{\max }=M_{R d} / h$ wallet).

Table 7. Overview of composite URM walls specimens

\begin{tabular}{|c|c|c|c|c|}
\hline \multicolumn{3}{|c|}{ Specimen Wall } & \multicolumn{2}{|c|}{$\begin{array}{l}\text { Axial Horizontal } \\
\text { load load Eccentricity }\end{array}$} \\
\hline No. & with & type & $\% \mathrm{kN} \mathrm{N}$ & - \\
\hline 1 & $\mathrm{~T} 1 \& \mathrm{C} 1$ & M10 & $15 \quad 601932$ & 0 \\
\hline 2 & $\mathrm{~T} 1 \& \mathrm{C} 1$ & M5 & $25 \quad 511725$ & 0 \\
\hline 3 & $\mathrm{~T} 1 \& \mathrm{C} 1$ & M10 & $15 \quad 561830$ & $t / 12$ \\
\hline 4 & $\mathrm{~T} 1 \& \mathrm{C} 1$ & M10 & $15 \quad 381447$ & $t / 6$ \\
\hline 5 & $\mathrm{~T} 1 \& \mathrm{C} 1$ & M10 & 251012558 & 0 \\
\hline 6 & $\mathrm{~T} 1 \& \mathrm{C} 1$ & M10 & 401612558 & 0 \\
\hline 7 & $\mathrm{~T} 1 \& \mathrm{C} 1$ & M10 & 552212558 & 0 \\
\hline 8 & $\mathrm{~T} 1 \& \mathrm{C} 1$ & M10 & 702822558 & 0 \\
\hline 9 & $\mathrm{~T} 2 \& \mathrm{C} 1$ & M10 & $15 \quad 942544$ & 0 \\
\hline 10 & $\mathrm{~T} 3 \& \mathrm{C} 1$ & M10 & $15 \quad 942924$ & 0 \\
\hline 11 & $\mathrm{~T} 2 \& \mathrm{C} 1$ & M10 & $15 \quad 702050$ & $t / 6$ \\
\hline 12 & $\mathrm{~T} 3 \& \mathrm{C} 1$ & M10 & $15 \quad 702356$ & $t / 6$ \\
\hline 13 & $\mathrm{~T} 2 \& \mathrm{C} 1$ & M10 & $15 \quad 862500$ & $t / 12$ \\
\hline 14 & $\mathrm{~T} 3 \& \mathrm{C} 1$ & M10 & $15 \quad 862873$ & $t / 12$ \\
\hline 15 & $\mathrm{~T} 2 \& \mathrm{C} 1$ & M10 & 251162993 & $t / 6$ \\
\hline 16 & $\mathrm{~T} 1 \& \mathrm{C} 1$ & M10 & 401202558 & $t / 6$ \\
\hline 17 & $\mathrm{~T} 1 \& \mathrm{C} 1$ & M10 & $25 \quad 932558$ & $t / 12$ \\
\hline 18 & $\mathrm{~T} 1 \& \mathrm{C} 1$ & M10 & 401482558 & $t / 12$ \\
\hline 19 & $\mathrm{~T} 1 \& \mathrm{C} 1$ & M5 & $25 \quad 782318$ & $t / 12$ \\
\hline 20 & $\mathrm{~T} 1 \& \mathrm{C} 1$ & M5 & 401252558 & $t / 12$ \\
\hline 21 & $\mathrm{~T} 1 \& \mathrm{~B} 1$ & M10 & $15 \quad 661902$ & 0 \\
\hline 22 & T1\& C2 & M10 & 151383472 & 0 \\
\hline
\end{tabular}
proposed of current research. 


\subsection{Overview of composite URM specimens}

The total number of specimens proposed to be tested are 22, with applying two configurations of masonry mortar bond, three types of thermal brick, three types of masonry unit, three eccentricities, maximum horizontal load (expected during the test), and five levels of vertical load as presented in Table 7.

\section{CONCLUSION}

In order to evaluate the influence of thermal insulation elements on the structural stability of unreinforced masonry wall, a first presentation of a running experimental program is given. Twenty-two small-scale masonry wallets characterized by various combinations of mortar, thermal bricks and load eccentricities are to be tested under axial compression and lateral out-of-plane loading. The specimens are non-homogenous masonry wallets combining classical load-bearing masonry with a bottom layer of improved thermal insulation properties. Approximate design procedures aiming at estimating the resistance of the specimens have been provided based on a tentative extension of the frame of Eurocode 6. The work is seen as a contribution to improving the development of Eurocode 6 concerning stability of masonry wall in presence of thermal elements. The preparation of the test set-up introduced in the paper is in progress at the moment of finalizing the present contribution, but a first insight in the test results will be presented during the conference as well as in a more detailed way in forthcoming publications.

\section{REFERENCES}

Bean Popehn, J.R. et al., 2008. Influence of transverse loading on the stability of slender unreinforced masonry walls. Engineering Structures, 30(10), pp.2830-2839.

Colville, J., 2001. Stability of Unreinforced Masonry Under Compressive Load. TMS Journal, (September).

Eurocode 6, 2005. EN 1996-1-1. (2005). Eurocode 6: Design of masonry structures. General rules for reinforced and unreinforced masonry structures. European Committee for Standardization, Brussels, Belgium.

Marmox, 2015. Marmox thermo block. Available at: http:// www.marmox.co.uk/uploads/product_images/33/Thermoblockbrochure2015.pdf.

Memari, A.M., Grossenbacher, S. V. \& Iulo, L.D., 2008. Structural Testing of High Thermal Mass Walls Used in Sustainable Designs. Structures Congress 2008, pp.1-9.

Penna, A. et al., 2008. Seismic performance of AAC infill and bearing walls with different reinforcement solutions. 14th International Brick \& Block Masonry Conference, (September 2015).

Schultz, A.E. \& Mueffelman, J.G., 2003. Elastic Stability of URM Walls Under Transverse Loading. TMS Journal, (September), pp.31-40.

STS22, 2016. STS 22 Metselwerk voor laagbouw, Brussels, Belgium.

Tanner, J.E. et al., 2005. Seismic testing of autoclaved aerated concrete shearwalls: A comprehensive review. ACI Structural Journal, 102(3), pp.374-382.

Tomaževič, M., 1999. Earthquake-resistant design of masonry buildings,

Zovkic, J., Sigmund, V. \& Guljas, I., 2013. Cyclic testing of a single bay reinforced concrete frames with various types of masonry infill. Earthquake Engineering and Structural Dynamics, 42(8), pp.1131-1149. 